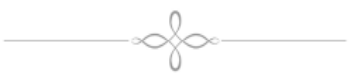

\section{Decifrando o georreferenciamento}

Resumo: Com a aquisição de um arquivo espacial a primeira indagação é alusiva à referência espacial, ou seja, certificação das informações pertinentes à sua localização na superfície da Terra. Comumente utiliza-se o Sistema de Referência Terrestre para identificar este posicionamento. Caso o arquivo não contenha tais informações, deve efetuar o processo denominado de georreferenciamento, composto basicamente de três etapas: transformação de coordenadas, mapeamento inverso e reamostragem. O sucesso do georreferenciamento implica diretamente na qualidade cartográfica. Assim, o objetivo deste artigo é fazer uma revisão conceitual e metodológica sobre o processo de georreferenciamento e a sua implicação na qualidade de um documento cartográfico.

\section{Deciphering the georeferencing}

Abstract: With the acquisition of a spatial file the first question is alluding to spatial reference, in other words, the relevant certification to its location on the Earth's surface information. Commonly we use the Terrestrial Reference System to identify this position. If the file does not contain such information, should perform the process called georeferencing, basically composed of three stages: coordinate transformation, inverse mapping and resampling. The success of georeferencing directly involves cartographic quality. Thereby, the purpose of this article is to do a conceptual and methodological review of the process of georeferencing and its implication as a cartographic document.
Danilo Heitor Caires Tinoco

Bisneto Melo*

Edmilson Martinho Volpi**

Hailton Mello da Silva***

Leonardo Araújo Menezes****

Pablício Vieira Moura*****

* Mestre em Sensoriamento Remoto pelo Instituto Nacional de Pesquisas Espaciais (INPE) e doutorando em Geografia na Universidade Federal da Bahia (UFBA). Professor Assistente no Departamento de Geologia e Geofísica Aplicada da UFBA.

** Mestre em Engenharia Urbana pela Universidade Federal de São Carlos (UFSCAR).

*** Mestre em Geoquímica e Meio Ambiente pela UFBA e doutorando em Geologia na UFBA. Professor Adjunto no Departamento de Geologia e Geofísica Aplicada da UFBA.

**** Granduando em Geologia pela UFBA.

***** Graduando em Geografia pela UFBA.

\section{Palavras-chave:}

Sistema de Informação Geográfica, georreferencimanto. correção geométrica, padrão de exatidão cartográfica.

Key-Words:

Geographic Information System, georeferencing, rubber shetting. cartographic accuracy standards. 


\section{Intodução}

Quando um arquivo matricial ou vetorial é adquirido para ser inserido num Banco de Dados Geográfico (BDG), o primeiro questionamento a ser realizado sobre ele é: $\mathrm{O}$ arquivo está Georreferenciado?

O inquisidor está querendo saber se o arquivo possui referência espacial. Informação vital para inserir, articular e manipular um arquivo no softwware de Sistema de Informação Geográfica (SIG) ou incluí-lo num BDG (CONGALTON; GREEN, 1992; LLOPIS, 2006; TEIXEIRA; MORETTI; CHRISTOFOLETTTI, 1992). Tal informação é considerada um metadado (CONCAR, 2009, 2011, MOURA, 2005; SILVA; MENDONÇA, 2012), por se tratar de:

\footnotetext{
[...] conjunto de informações descritivas sobre os dados, incluindo as características de seu levantamento, produção, qualidade e estrutura de armazenamento, essenciais para promover a sua documentação, integração e disponibilização, bem como possibilitar sua busca e exploração (BRASIL, 2008, Art. 2, Cap. II).
}

A referência espacial refere-se às informações pertinentes à localização exata de um objeto na superfície da Terra, identificando o seu posicionamento, sendo comumente utilizado os Sistemas de Referência Terrestre ou Geodésicos (IBGE, 2011). Por sua vez, estão associados a uma superfície que mais se aproxima da forma Terrestre, e sobre a qual são desenvolvidos todos os cálculos das suas coordenadas.

Quando o arquivo geográfico possui referência espacial, comumente é denominado de arquivo georreferenciado, podendo ser inserido diretamente no BDG, e integrada a outras informações, como ilustrado na Figura 1, em que uma CT georreferenciada foi sobreposta a imagem de satélite.

Caso contrário, deve-se realizar o seu georreferenciamento, que envolve algumas operações de transformação geométrica que visa estabelecer uma relação entre o sistema de referencia do arquivo geográfico e um sistema de referência terrestre, ocasionando alteração de algumas de suas características como posição, forma ou tamanho.

O processo de georreferenciamento é considerado de fundamental importância no tratamento da informação geográfica, pois está relacionado diretamente com a qualidade cartográfica.

Figura 1-Arquivo georreferenciado.

Geografia Ensino \& Pesquisa, v. 18, n.3, p. 85-102, set./dez. 2014.

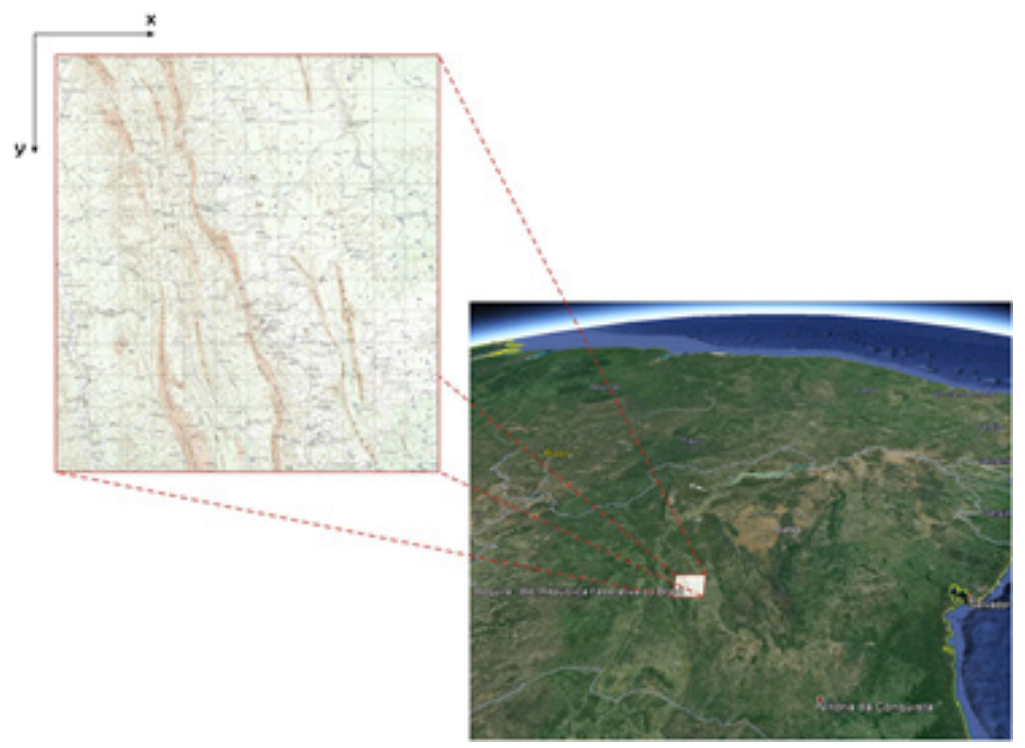


Entretanto, com os avanços tecnocientíficos a execução destas etapas tornaram-se rotineiras e, muitas vezes, realizada de modo mecânica o que pode conduzir a desatenção dos profissionais que produzem e confeccionam documentos cartográficos. Por isto, considera-se imprudente aceitar o resultado do georreferenciamento de modo acrítico.

Desta forma, o objetivo principal deste trabalho é apresentar as bases conceituais e metodológicas do processo de georreferenciamento e a sua implicação na qualidade de um documento cartográfico.

\section{Sistema de Coordenadas}

Existem vários tipos de Sistema de Coordenadas que permitem expressar a posição precisa de um alvo sobre a superfície terrestre. Uma das mais difundidas e idealizadas sobre a forma desta superfície como um todo é denominado de Sistema de Coordenadas Esférico ou Geodésico. Este sistema configura, matematicamente, a Terra como uma superfície quádrica em três dimensões obtidas através da rotação de um elipse ao redor do seu eixo menor, e a sua unidade de medida é a angular (IBGE, 1999, 2011; LLOPIS, 2006; SILVA, 2003). A localização de alvo é efetuada por meio de latitude e longitude. "Tratando-se de Astronomia, estas coordenadas são denominadas de latitude e longitude astronômicas" (VEIGA; ZANET'TI; FAGGION, 2012, p. 8).

Para mapear a superfície terrestre nesta esfera é necessário buscar um modelo matemático de forma que esta superfície terrestre tangencie a superfície esférica, sendo utilizada um desenho geométrica denominada de Elipsóide de Revolução, cujo formato, dimensão e o posicionamento definem um Sistema Geodésico, designado também de datum geodésico (IBGE, 1999). Devido à sua habilidade de referenciar as localizações, este sistema é denominado normalmente como Sistema de Coordenadas Geográficas, ou como Sistema de Referência Global (LLOPIS, 2006).

Em virtude dos avanços tecnocientíficos, como a ampliação, modernização e monitoramento do Sistema Geodésico Brasileiro (composto por uma rede planimétrica, altimétrica e gravimétrica e maregráfica), o posicionamento do datum geodésico, bem como suas normativas foi modificado, sendo o último adotado o SIstema de Referência Geocêntrico para as AméricaS (SIRGAS), realizado no ano de 2000, notoriamente denominada de SIRGAS 2000 (DALAZOANA; FREITAS, 2002; IBGE, 1999, 2005 e 2013; D’ALGE, 2013).

Contudo, como suas medidas estão em Graus (sexagesimais ou decimais), o que inviabiliza a extração de medidas métricas. Para solucionar este problema, efetua-se uma transformação da superfície tridimensional curva da Terra em uma superfície plana, ou bidimensional. Por conseguinte, as coordenadas geográficas (latitude e longitude) são substituídas por coordenadas cartesianas ou polares (x,y), ou qualquer outro meio, que as represente no plano (LLOPIS, 2006). A este relacionamento matemático entre as posições referidas a um modelo de superfície terrestre e posições referidas a uma superfície plana são denominadas de projeção. O conjunto de elementos interconectados que o organiza recebe o nome de Sistema de Coordenadas Planas ou Cartesianas (ANDERSON, 1982; IBGE, 1999; LLOPIS, 2006).

Por convenção matemática estabelece o eixo horizontal como eixo X, definindo a família de coordenadas denominadas de abscissas e o eixo vertical como eixo Y, definindo a família de coordenadas denominadas de ordenadas. Sendo cada eixo uma linha reta e perpendicular um ao outro, segue-se que todas as linhas de uma mesma família serão paralelas entre si e todos os pontos de interseção dentro da rede são obtidos através de famílias de linhas retas perpendiculares.

Por tratado, os eixos coordenados dividem o espaço em quatro regiões, denominados quadrantes, tendo como ponto de origem o mesmo que a latitude e longitude $0^{\circ}$, como ilustrado na Figura 2. A convenção de sinal para as coordenadas x e y, estabelece que as coordenadas serão positivas e negativas à direita e à esquerda do eixo $\mathrm{Y}$ e acima e abaixo do eixo $\mathrm{X}$, respectivamente.

Geografia Ensino \& Pesquisa, v. 18, n.3, p. 85-102, set./dez. 2014.

Melo, D. H. C. T. B.; Volpi, E. M.; Silva, H. M. da; Menezes, L. A.; Moura, P. V.

ISSN 2236-4994 | 87 

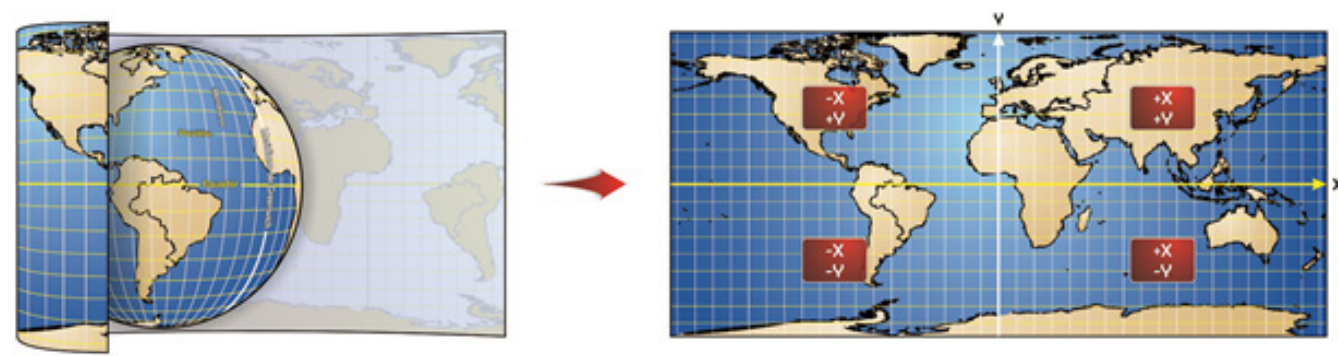

Fonte: elaborado pelos autores.

Todavia, a projeção de superfície esférica apresenta algumas distorções, envolvendo extensões ou contrações, sendo necessário adotar alguns métodos e técnicas de representação, no sentido de se alcançar resultados que possuam certas propriedades favoráveis para um propósito específico (ANDERSON, 1982; IBGE, 1999).

Desta forma, cada sistema de projeção procura atender, prioritariamente, uma destas propriedades. O IBGE (1999), Iliffe e Lott (2008), Sickle (2010) e Snyder, (1987) apresentam uma classificação das projeções, quanto às características da superfície terrestre projetadas sobre o nível do mar aproximadamente, conforme Quadro 1.

Quadro 1-Classificação das projeções.

Geografia Ensino \& Pesquisa, v. 18, n.3, p. $85-102$, set./dez. 2014

$$
\text { Decifrando o }
$$
georreferenciamento

\begin{tabular}{|c|c|c|}
\hline \multirow[b]{2}{*}{ I - Quanto ao método } & \multicolumn{2}{|c|}{ Geométricas Perspectivas e pseudo-perspectiva } \\
\hline & \multicolumn{2}{|c|}{$\begin{array}{l}\text { Analíticas simples ou regulares e modificadas ou } \\
\text { irregulares }\end{array}$} \\
\hline \multirow{5}{*}{$\begin{array}{c}\text { II - Quanto às propriedade } \\
\text { espaciais }\end{array}$} & \multicolumn{2}{|l|}{ Convencionais } \\
\hline & \multicolumn{2}{|l|}{ Equidistantes } \\
\hline & \multicolumn{2}{|l|}{ Equivalentes } \\
\hline & \multicolumn{2}{|c|}{ Conforme (Ortomórficas) } \\
\hline & \multicolumn{2}{|l|}{ Afiláticas } \\
\hline \multirow{3}{*}{$\begin{array}{l}\text { III - Quanto à situação do } \\
\text { ponto de vista }\end{array}$} & \multicolumn{2}{|l|}{ Gnomônica } \\
\hline & \multicolumn{2}{|l|}{ Estereográfica } \\
\hline & \multicolumn{2}{|l|}{ Ortográfica } \\
\hline \multirow{4}{*}{$\begin{array}{l}\text { IV - Quanto à superfície d } \\
\text { projeção }\end{array}$} & \multirow{3}{*}{ Por desenvolvimento } & Cônica e policônica \\
\hline & & Cilíndricas \\
\hline & & Poliédricas \\
\hline & \multicolumn{2}{|l|}{ Planas ou azimutais } \\
\hline \multirow{9}{*}{$\begin{array}{l}\text { V - Quanto à posição da } \\
\text { superfície de projeção }\end{array}$} & \multirow{3}{*}{ Planas ou azimutais } & Polares \\
\hline & & $\begin{array}{l}\text { Equatoriais ou } \\
\text { meridianas }\end{array}$ \\
\hline & & Horizontais ou obliquas \\
\hline & \multirow{3}{*}{ Cônicas e policônicas } & Transversas \\
\hline & & Normais \\
\hline & & Horizontais ou obliquas \\
\hline & \multirow{3}{*}{ Cilíndricas } & Transversas \\
\hline & & Normais \\
\hline & & Horizontais ou obliquas \\
\hline
\end{tabular}

Fonte: elaborado pelos autores. 
A Projeção Cartográfica oficial adotada pelo Brasil para escalas de 1:1.000.000 ou maiores foi a Universal Transversa de Mercator, extensamente conhecida pela sua sigla UTM (ANDERSON, 1982; IBGE, 1999).

Os avanços tecnocientíficos em sensoriamento remoto e em processamento digital de imagem possibilitaram o aprimoramento nos métodos de georreferenciamento. Em virtude disto, para particularizar e diferenciá-las são empregadas algumas terminologias (SCHOWENGERDT, 2007), tais como:

- Registro: alinhamento de uma imagem com base em outra imagem alinhada;

- Retificação: alinhamento do sistema de coordenadas de um documento cartográfico digital. Como as informações contidas neste documento já passou por um tratamento cartográfico, necessitando, aparentemente, apenas transformar as suas coordenadas de referências para um Sistema de Referência Terrestre;

- Geocodificação: processo de conversão de endereço (como CEP, cidade, bairro, rua, número) num sistema de coordenadas; e

- Ortorretificação: além da transformação no sistema de coordenadas planas, efetua-se também a correção altimétrica (topográfica). Neste caso, a projeção adotada é a ortográfica (IBGE, 1999).

Nesta perspectiva, a terminologia empregada para especificar o processo de georreferenciamento de uma CT é a Retificação, portanto, nas próximas etapas será descrita somente esta.

\section{Etapas do georreferenciamento}

De acordo com D’Alge (2013) e Schowengerdt (2007), o processo de georreferenciamento pode ser dividido três grandes etapas:

$1^{\circ}$. Seleção da transformação de coordenadas adequada: também denominado de mapeamento direto, seleciona-se o modelo matemático a ser utilizado para estabelecer uma relação entre o Sistema de coordenadas da imagem digital com o Sistema de Referência Terrestre;

$2^{\circ}$. Mapeamento Inverso: efetua a "construção" da nova imagem com base na operação utilizada na etapa anterior, definindo a localização dos pixels.

$3^{\circ}$. Reamostragem: definição dos valores de cada pixel da nova imagem, com base na imagem original.

\section{Transformação de Coordenadas}

De acordo com Sickle (2010), a transformação corresponde a mecanismos matemáticos usados para mover um Sistema de coordenadas para outro. De acordo com D'Alge (2013) existem vários métodos de transformação de coordenadas, sendo os modelos matemáticos os mais utilizados, tais como:

- Modelo de correções independentes, ou correção dos erros sistemáticos: relacionados as diversas distorções sistemáticas que podem ocorrer na aquisição de uma imagem de sensoriamento remoto, devido as suas características e posicionamento das plataformas; e

- Modelo fotogramétrico: inspira-se no uso das equações de colinearidade, semelhante ao aplicado na fototriangulação (CASACA; MATOS; BAIO, 2005; D'ALGE, 2013; MARCATO JUNIOR et al, 2011).

Geografia Ensino \& Pesquisa, v. 18, n.3, p. 85-102, set./dez. 2014.

Melo, D. H. C. T. B.; Volpi, E. M.; Silva, H. M. da; Menezes, L. A.;
Moura, P. V.

ISSN 2236-4994 
- Modelo Polinomial, ou correção de precisão: constitui na correção das coordenadas através da relação geométrica entre as coordenadas da imagem bidimensional e um Sistema de Referência Terrestre, tendo como resultado uma imagem corrigida. Esta relação se baseia em funções polinomiais cujos parâmetros são determinados a partir de Pontos de Controle do Terreno (do inglês ground control point - GCP).

De acordo com D'Alge (2013), o modelo polinomial está presente na maioria dos SIG's, por não utilizar informações inerentes à aquisição da imagem, tanto imagem digitalizada como imagem de sensoriamento remoto, e nem faz distinção sobre o status ou o nível de correção geométrica da imagem. Todavia, alguns autores salientam algumas desvantagens no seu uso, como:

- Degradação na imagem (SCHOWENGERDT, 2007);

- Não corrige distorções topográficas (SCHOWENGERDT, 2007); e

- Uso recomendado apenas para corrgir pequenas distorções (ILIFFE; LOTT, 2008).

\section{Modelo Polinomial}

O método polinomial é materializado por meio das equações de ajustamento que podem ser consideradas como uma aproximação de um conjunto de PC a uma função média que mais se aproxime de todos os dados, obtendo-se assim uma solução para os sistemas sobredeterminados formados durante a transformação. Neste sentido, adota-se o modelo Paramétrico de Ajustamento pelo Método dos Mínimos Quadrados para determinar os coeficientes de duas equações de transformação no plano que interrelacionam as coordenadas.

De acordo com D’Alge (2013) o sistema de equações coincide com o número de coeficientes a calcular, que por sua vez está em conformidade com o número mínimo de PC necessários para a solução determinística Para determinar o grau de polinômio utiliza-se a seguinte equação (IBGE, 2001):

$$
\frac{(N+1) \times(N+2)}{2}=\text { Número mínimo de } P C
$$

Onde N corresponde ao grau de polinômio desejado.

Equação 1

Os coeficientes correspondem aos parâmetros que podem ser utilizados para a transformação geométrica, sendo eles: translação, escala, rotação, cisalhamento e espelhamento (YAROSLAVSKY, 2004), como demonstra a Figura 3.

Figura 3-Parâmetros utilizados na transformação geométrica no plano.
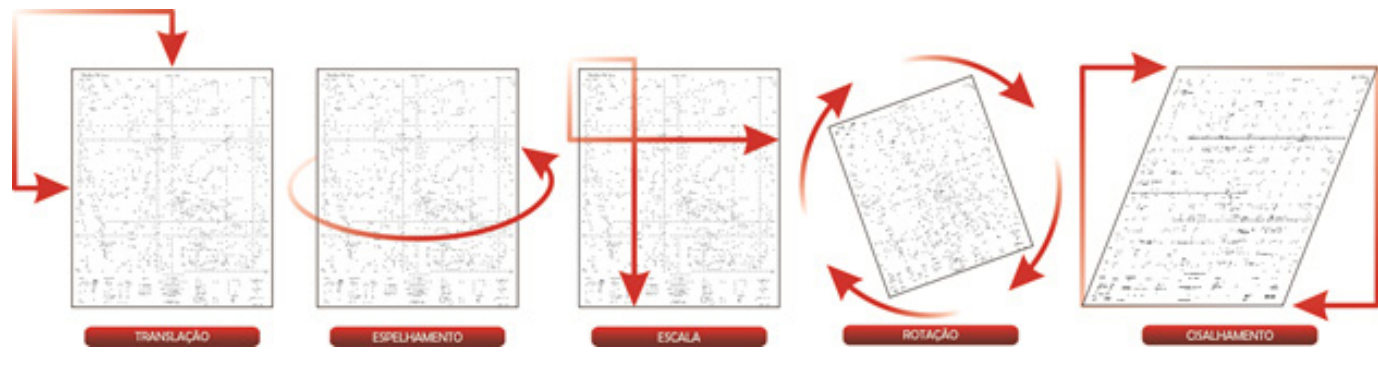

Fonte: elaborado pelos autores. 
De acordo com D’Alge (2013) a transformação polinomial, ou de afinidade, executa 6 parâmetros independentes (dois fatores de escala, uma rotação, duas translações e uma rotação residual, que é responsável pela quebra de ortogonalidade), como mostra a Figura 4. Esta transformação reporta ao polinômio de $1^{\circ}$ (linear) e dado pela equação:

$$
\begin{aligned}
& c=a_{0}+a_{1} x+a_{2} y \\
& l=b_{0}+b_{1} x+b_{2} y
\end{aligned}
$$

Onde a0,a1, a2, b0, b1 e b2 correspondem aos parâmetros.

Equação 2

Para Iliffe e Lott (2008) esta transformação é ideal para mapas digitalizados, pois corrige os efeitos de retração e expansão do papel que, porventura, possam existir.

Existem outras transformações que utilizam menos parâmetros e também utilizam menos PC, como a Ortogonal, similaridade, transformação afim ortogonal (D’ALGE, 2013), efetuando apenas o posicionamento (rotação e translação) e escala (BOUTOURA; LIVIERATOS, 2006).

Figura 4-Transformação geométrica da imagem original para a imagem corrigida.

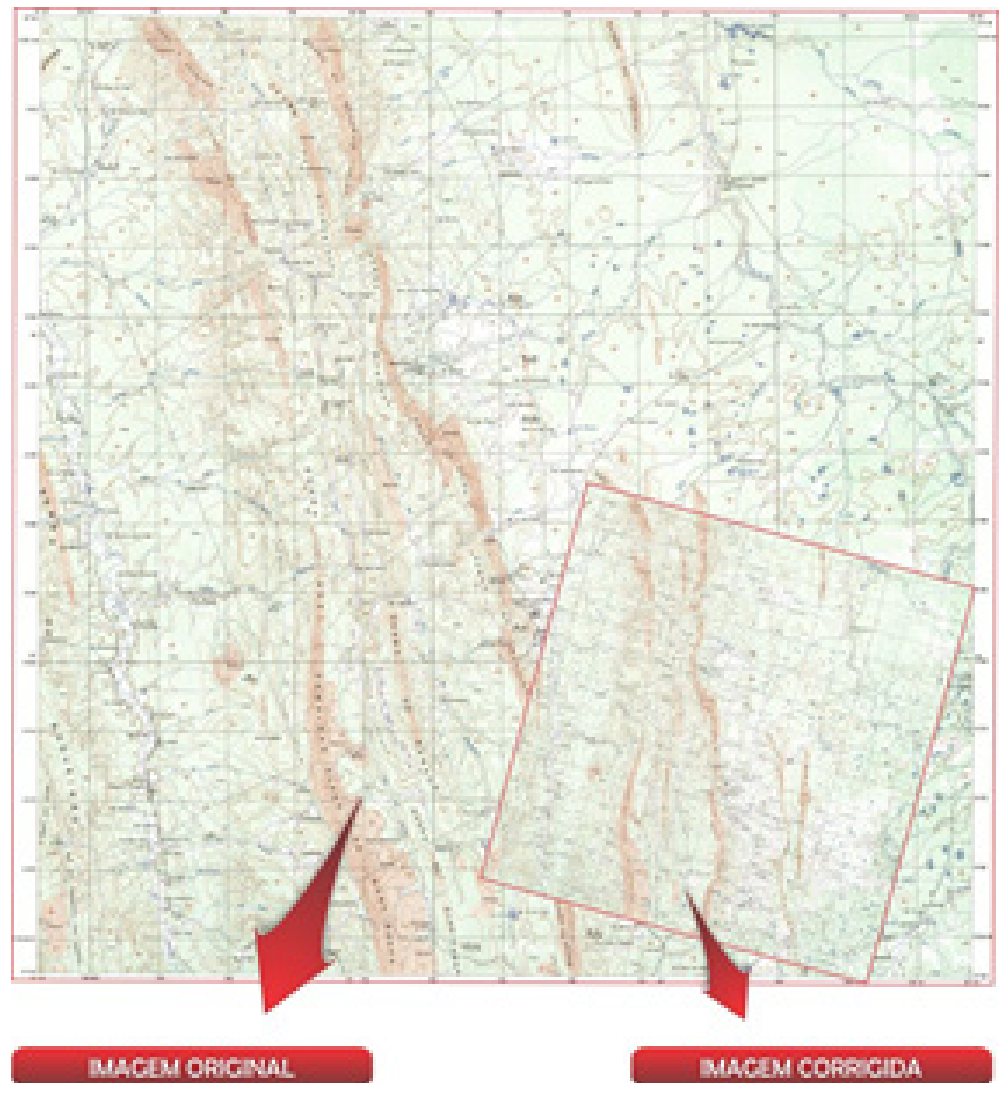

Fonte: elaborado pelos autores.

Como também existem transformações que exigem mais parâmetros, como a de Molodenski e transformações polinomiais maiores que $1^{\circ}$ grau, porém, devem ser usados com cautela, pois introduzem a quebra de paralelismo, sendo empregado apenas quando houver a necessidade de efetivar outras transformações geométricas (D’ALGE, 2013; BRITO; COELHO FILHO, 2002), devido principalmente as suas propriedade não lineares (BOUTOURA; LIVIERATOS, 2006).

Geografia Ensino \& Pesquisa, v. 18, n.3, p. 85-102, set./dez. 2014.

Melo, D. H. C. T. B.; Volpi, E. M.; Silva, H. M. da; Menezes, L. A.
Moura, P. V. 


\section{Pontos de Controle do Terreno}

A partir de um sistema de coordenadas pode-se definir um ponto por meio de suas coordenadas. Na imagem a linha (l) e coluna (c) correspondem ao seu sistema de referência. Com isto, os Pontos de Controle do Terreno, ou simplesmente Pontos de Controle (PC) reportam a pontos homólogos, que são pontos locados na imagem, que também podem ser identificados no Sistema de Referência Terrestre (FONSECA; MANJUNATH, 1996)

Por convenção, procura-se fazer a locação dos PC nas extremidades das feições (imagem de sensoriamento remoto) ou dos traços ou símbolos cartográficos, podendo ser classificados em:

- Naturais: são os elementos existentes na natureza como por exemplo: pequenas ilhas, confluência e meandros de rios, ilhas; e

- Artificiais: são os elementos criados pelo homem como um cruzamento no sistema viário, uma ponte, uma praça, farol, entre outras.

Quando não for possível identificar tais extremidades, traços ou símbolos cartográficos, devido a resolução espacial da imagem de satélite, ou escala da CT, a recomendação da utilização do centro geográfico (como por exemplo de uma ilha, quadra, pista de pouso).

Com relação a locação dos PC, pode-se classificá-los em:

- Primária: locação diretamente em campo, com o uso de equipamento de Sistema de Posicionamento Global ( do inglês global positioning system - GPS); e

- Secundária: uso de arquivo digital georreferenciado (matricial ou vetorial), que seja possível identificar as mesmas feições ou simbolos cartográficos para locação dos PC.

Quando for utilizar uma CT digital para georreferenciar um outro arquivo, como, por exemplo, uma imagem de sensoriamento remoto, é importante verificar a data de confecção deste documento, devido às mudanças no uso e ocupação da Terra. Estas mudanças podem ocasionar uma operação de locação de PC mais difícil, pois deve-se lembrar que o mapa é uma abstração das características tempo-espacial (SCHOWENGERDT, 2007).

Ao retificar uma CT digital, ou um Fotolito, recomenda-se empregar o Sistema de Referência Terrestre no qual foi confeccionada, pois as representações espaciais estão em conformidade com o mesmo.

As informações sobre a referência espacial da carta e suas características extrínsecas e intrínsecas estão inseridas na parte inferior central da carta, como mostra a Figura 5 (ANDERSON, 1982; SANTIL; QUEIROZ, 1996b). Este modo de locação dos PC também pode ser considerado secundário.

A seleção de PC's para uma tarefa de retificação é normalmente um processo interativo, na qual é selecionado um conjunto inicial e bem distribuido, de forma a ocupar homogeneamente toda área de trabalho (LUIZ; OLIVEIRA; OKIDA, 2003). Isto envolve a percepção do usuário e um número maior de PC que a quantidade necessária para atender a equação de transformação (CUARTERO; FELICISIMO, 2003). Caso contrário, uma distribuição heterogênea ou locais sem PC, terão erros de posicionamento, afetando assim, a qualidade do documento cartográfico.

O termo qualidade tem vários significados, mas quando empregado como adjetivo de um produto, como no caso do documento cartográfico, pondera sobre as adequações de uso, a totalidade de seus aspectos e características que propiciam a habilidade de satisfazer às necessidades exigidas ou implícitas. Porém, suas características podem variar tanto para melhor como para pior. Isto inclui também aos procedimentos adotados no seu desenvolvimento (SAMOHYL, 2009). O que indiretamente implica na localização e eliminação das causas que podem provocar tais problemas de qualidade (OAKLAND, 1994).

Uma forma de verificar esta variabilidade é estabelecer critérios e implementar mecanismos para a sua aferição, o que requer a mensuração de suas características em termos quantitativos (SAMOHYL, 2009). 
Figura 5-Sistema de Coordenadas e informação sobre a Referência Espacial.

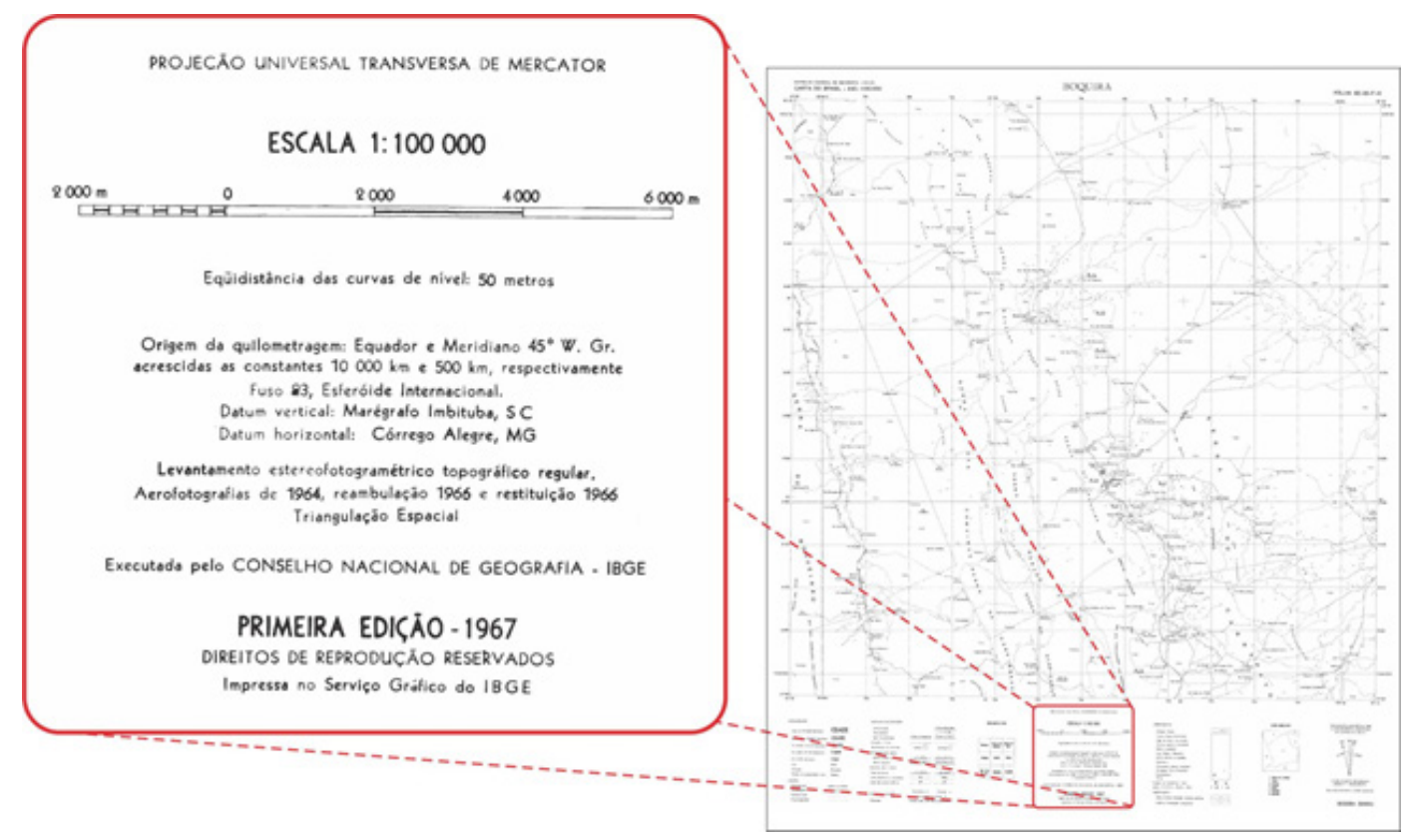

Fonte: elaborado pelos autores.

\section{Qualidade Cartográfica}

O termo qualidade tem vários significados, mas quando empregado como adjetivo de um produto, como no caso do documento cartográfico, pondera sobre as adequações de uso, a totalidade de seus aspectos e características que propiciam a habilidade de satisfazer às necessidades exigidas ou implícitas. Porém, suas características podem variar tanto para melhor como para pior. Isto inclui também aos procedimentos adotados no seu desenvolvimento (SAMOHYL, 2009). O que indiretamente implica na localização e eliminação das causas que podem provocar tais problemas de qualidade (OAKLAND, 1994).

Uma forma de verificar esta variabilidade é estabelecer critérios e implementar mecanismos para a sua aferição, o que requer a mensuração de suas características em termos quantitativos (SAMOHYL, 2009).

Assim, o processo de georreferenciamento deve passar por controle de qualidade, com a finalidade de verificar a veracidade das etapas que antecedem a produção cartográfica.

Neste sentido, uma forma de determinar a qualidade deste processo é efetuar um tratamento estatístico dos PC (uma vez que representam amostras alusivas a localização e encontram-se dispersas espacialmente), avaliando a exatidão e precisão.

Exatidão (ou acuidade) corresponde ao grau de aproximação da medida com seu valor real, ou seja, faz-se uma avaliação do erro sistemático (SANTIL; QUEIROZ, 1996a).

Precisão reporta ao grau de dispersão entre medidas repetidas sob as mesmas condições, e normalmente quantificada pelo desvio-padrão, variância e o coeficiente de variação. Portanto, a avaliação da precisão de uma medida não leva em consideração o valor verdadeiro (BRITO, et al., 2002).

Assim, a exatidão e precisão examinam aspectos diferentes, mas fundamentais, que precisam ser levados em consideração na avaliação da qualidade do resultado de uma medição. Assim, existe a possibilidade que o resultado de uma medição seja exato e preciso, exato e impreciso, inexato e preciso ou inexato e impreciso. A Figura 6 apresenta um exemplo clássico de tiro ao alvo.

Geografia Ensino \& Pesquisa, v. 18, n.3, p. 85-102, set./dez. 2014.

Melo, D. H. C. T. B.; Volpi, E. M.; Silva, H. M. da; Menezes, L. A.; Moura, P. V. 
Figura 6-Análise da precisão e exatidão.

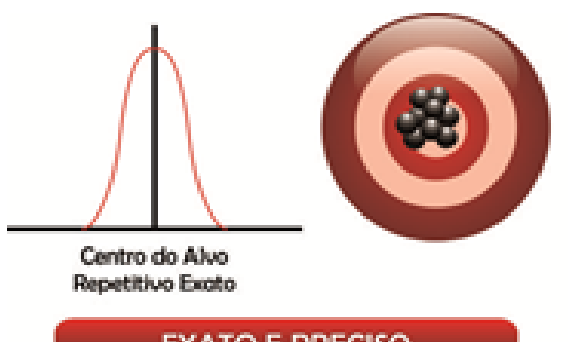

EXATO E PRECISO
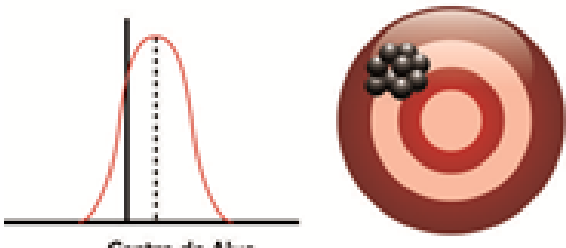

Centro do Alvo

Repetitivo Inexato

PRECISO, MAS NĀO-EXATO
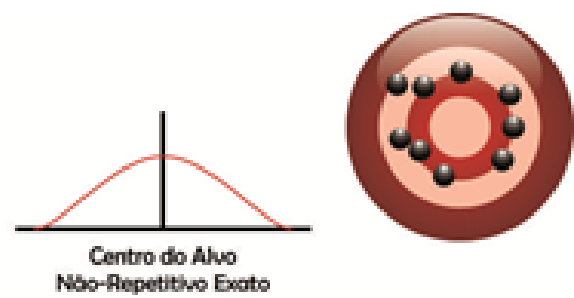

No-Aepetit

EXATO, MAS NĀO-PRECISO

Fonte: elaborado pelos autores.

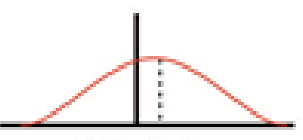

Centro do Alvo

Noo-flepetitivo Inewoto

NĀO-PRECISO E NĀO-EXATO

Com base nisto, para cartografia a exatidão corresponde a diferença na localização entre o alvo mapeado e o seu posicionamento real, logo, compara-se as coordenadas. Consequentemente, para examinar a exatidão de um documento cartográfico, utilizam-se métodos de amostragem, podendo ter erros maiores ou menores. Para tanto, analisa-se, estatisticamente, a sua dispersão, verificando a sua confiabilidade. O que corresponde a avaliação da precisão.

Desta forma, faz-se necessário analisar os valores das coordenadas dos PC locado na imagem e a sua correspondente no Sistema de Referência Terrestre. Para explicar melhor este cálculo, toma-se como base a Figura 7, que demonstra a localização de um PC na imagem (Origem (X,Y)), e o seu posicionamento "real" no Sistema de Referencia Terrestre (Mapa (X,Y)). Foi arquitetado ao lado, um eixo de coordenadas cartesiano de forma que as duas medidas fiquem do mesmo lado.

Figura 7-Diferença de coordenadas.

Geografia Ensino \& Pesquisa, v. 18 n.3, p. 85-102, set./dez. 2014

Decifrando o georreferenciamento

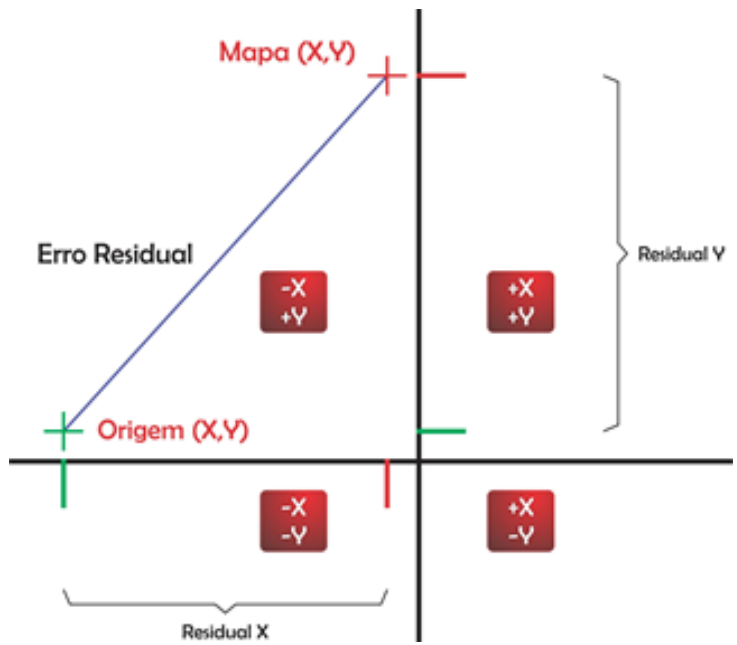

Fonte: elaborado pelos autores. 
Projetando as medidas nos eixos de coordenadas cartesianas (x,y), pode-se verificar a diferença de localização, tanto no eixo x como no eixo y. Esta diferença é denominada de Residual $\mathrm{X}$ (XOrigem - XMapa) e Residual Y (YOrigem - YMapa). A distância, em linha reta, entre as coordenadas Origem $(\mathrm{X}, \mathrm{Y})$ e Mapa $(\mathrm{X}, \mathrm{Y})$, corresponde ao erro de localização, denominado de Residual. O seu valor pode ser calculado empregando o Teorema de Pitágoras:

$$
\operatorname{Residual}(X, Y)=\sqrt{\left(X_{\text {Origem }}-X_{\text {Mapa }}\right)^{2}+\left(Y_{\text {Origem }}-Y_{\text {Mapa }}\right)^{2}}
$$

\section{Equação 3}

Os residuais calculados para cada PC são úteis para monitorar o resultado da transformação, e assim, pode-se ajustar ou suprimir o PC que esteja com um valor de residual elevado. Quando ocorre um valor residual (X ou Y) muito elevado, provavelmente, seja erro na identificação do PC. Neste caso, ele deve ser corrigido ou suprimido.

O eixo das abscissas também pode auxiliar na identificação da direção do erro. Para tanto, basta projetar o eixo das abscissas em cima do PC de origem e verificar em que direção se encontra o PC do Mapa. Como por exemplo, na Figura 16, o PC do Mapa está deslocado em +X e + Y, ou simplesmente X e Y.

Para estimar e controlar a qualidade dos PC, aplica-se o método estatístico denominado de erro médio quadrático, comumente conhecido pelo acrônimo RMS (do inglês root mean square) fornece uma visão conjunta da acurácia da correção, sendo calculado pelas equações (IBGE, 2001):

$$
\begin{aligned}
& \operatorname{RMS}(X)=\frac{\left(\sum\left(\mathrm{X}_{\text {Origem }}-\mathrm{X}_{\text {Mapa }}\right)^{2}\right)}{(n-k)^{1 / 2}} \\
& \operatorname{RMS}(Y)=\frac{\left(\sum\left(\mathrm{Y}_{\text {Origem }}-\mathrm{Y}_{\text {Mapa }}\right)^{2}\right)}{(n-k)^{1 / 2}}
\end{aligned}
$$

Onde: " $n$ " corresponde a quantidade de PC's; " $k$ " é o número de termos da ordem do polinômio usado.

Equação 4

Da mesma forma que os resíduos, o RMS (X,Y) considera o RMS nas direções X e Y conjuntamente.

$$
R M S(X, Y)=\sqrt{\left(R M S(X)^{2}+\left(R M S(Y)^{2}\right.\right.}
$$


características, e também de padronizar o uso de terminologias. No Brasil, um órgão que tem a missão de prover confiança à sociedade brasileira no controle de qualidade é o Instituto Nacional de Metrologia, Qualidade e Tecnologia (INMETRO). Assim, o INMETRO no uso de suas atribuições e no intuito de uniformização da terminologia utilizada no campo a Metrologia Legal, adota o Vocabulário Internacional de Termos de Metrologia Legal (BRASIL, 2005), e define o termo acurácia como sinônimo de exatidão (COSTA; EPPRECHT; CAPINETTTI, 2009).

\section{Critério de Aceitação}

Como critério de aceitação, são elaboradas normas e regras que auxiliam no controle de qualidade. Assim, no dia 20 de junho de 1984 foi aprovado e publicado o Decreto no 89.817, o qual estabelece as Instruções reguladoras das Normas Técnicas da Cartografia Brasileira através de procedimentos exigíveis para execução, aceitação, elaboração e apresentação de documentos cartográficos no Território Brasileiro. Esse decreto institui que $90 \%$ dos elementos representados numa carta, quando testados no terreno, não deverão apresentar um erro de posicionamento superior ao Padrão de Exatidão Cartográfica (PEC) estabelecido (BRASIL, 1984).

Esse erro está diretamente relacionado a escala de trabalho, quanto à sua exatidão e é utilizado como medida básica. Um erro-padrão, para o controle de qualidade cartográfico, pode ser qualificado em Classes A, B e C (SANTOS et al., 2010). Desta forma, o erro-padrão aceitável na escala de uma carta para Classe A é de no máximo, $0,3 \mathrm{~mm}$; para Classe $\mathrm{B}$, de $0,5 \mathrm{~mm}$; e para Classe C é de 0,6 mm (BRASIL, 1984).

Uma vez computado os coeficientes de transformação, a imagem corrigida poderá ser convertida em uma nova imagem, o que envolve a transferência do valor do nível de cinza da imagem original para a imagem corrigida. Como geralmente há um rearranjo da posição dos pixels, ocasionado pela mudança no seu posicionamento, é necessário recalcular o seu número digital. Este processo é denominado de reamostragem ou interpolação de intensidade.

Por exemplo, ao se fazer a verificação do posicionamento na superfície terrestre de entidades representadas, no caso no extremo direito da pista de pouso, num mapa na escala 1:100.000, pode-se aceitar um erro-padrão máximo de $30 \mathrm{~m}$ para classe $\mathrm{A}$, de $50 \mathrm{~m}$ para classe B e de $60 \mathrm{~m}$ para classe C (Figura 8).

Figura 8-Erro-padrão máximo de deslocamento para as Classes A, B e C.

Geografia Ensino \& Pesquisa, v. 18, n.3, p. $85-102$, set./dez. 2014

$$
\text { Decifrando o }
$$
Decifrando o
georreferenciamento

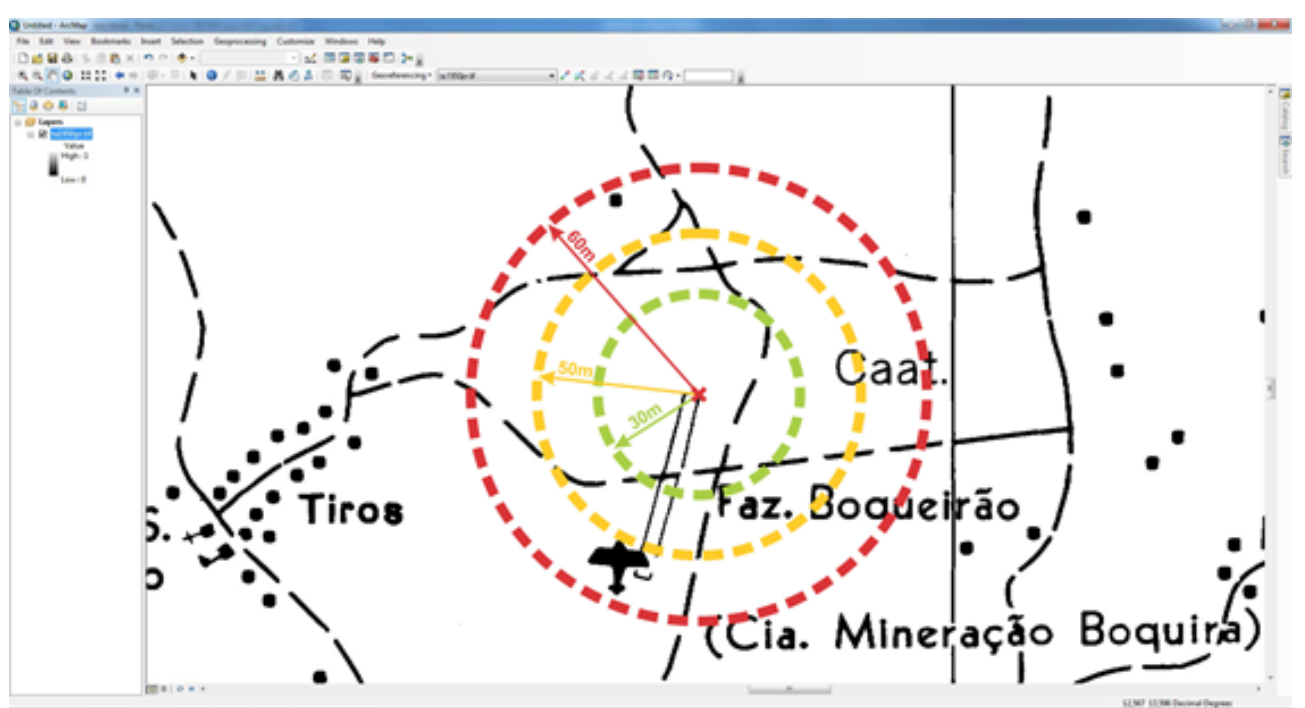

Fonte: elaborado pelos autores. 


\section{Mapeamento Inverso}

O equacionamento da transformação geométrica da imagem se completa com o mapeamento inverso, que calcula a posição correta de cada pixel para a nova imagem (ARAKI,1990; D’ALGE, 2013; IBGE, 2001). Ou seja, executa a reconstrução da nova imagem que, raramente, coincide hermeticamente com a imagem original, em decorrência do tipo de transformação geométrica e de sua precisão (MENESES; ALMEIDA, 2012).

Esta etapa formula uma função inversa sobre a equação utilizada na etapa anterior, por exemplo, quando se aplica a transformação geométrica $(\mathrm{T})$, o mapeamento inverso irá efetuar a transformação T-1 (D’ALGE, 2013).

De acordo com Araki (1990), dependendo das características aplicadas no mapeamento direto, a inversão ocorre numericamente e não de forma algébrica. Este processo ocorre automaticamente sem mediação com o usuário, fundamentado, na ideia de otimização computacional (D’ALGE, 2013).

Além disto, este procedimento é imprescindível para a realização da última etapa da transformação geométrica, a reamostragem.

\section{Reamostragem}

Enquanto o mapeamento inverso efetua o rearranjo dos pixels, a reamostragem implica na extração dos valores do NC localizada na imagem original e sua relocação nas coordenadas da imagem de saída. A reamostragem procede pixel a pixel, primeiro ao longo das linhas e depois ao longo das colunas, como uma janela móvel (ARAKI,1990; SCHOWENGERDT, 2007).

De acordo com Moik (1980), a reamostragem corresponde a um processo de conversão e recuperação dos valores de $\mathrm{NC}$ da imagem original para a nova imagem, fundamentada em interpoladores, uma função contínua (SCHOWENGERDT, 2007). $\mathrm{O}$ uso de interpolação permite dispor novos valores de NC a partir de uma sequência discreta de amostras pontuais previamente conhecidas.

Há três métodos universalmente citados: vizinho mais próximo (ou de interpolador de ordem 0), interpolação bilinear e convolução cúbica (ARAKI, 1990; D’ALGE, 2013; GOSHTASBY, 2005; IBGE, 2001; MOIK, 1980; SCHOWENGERDT, 2007).

Importante evidenciar que por tratar de processo de interpolação, há um pequeno dano na precisão métrica (MOIK, 1980).

\section{Vižinho mais próximo}

Considerada a técnica mais trivial, este interpolador atribui o valor do NC do pixel da imagem de entrada mais próximo para assinalá-lo ao pixel na nova imagem.

Baboo e Devi (2010) Ramsey (1998a) relatam como vantagem deste método a sua simplicidade e sua capacidade de preservar os valores originais. Isto pode ser comprovado na Figura 9 que mostra os valores dos NC da imagem original quando comparado a nova imagem que passou por esta reamostragem. Goshtasby (2005) destaca também a sua primazia de não desfocar a imagem.

Geografia Ensino \& Pesquisa, v. 18, n.3, p. 85-102, set./dez. 2014.

Melo, D. H. C. T. B.; Volpi, E. M.; Silva, H. M. da; Menezes, L. A. 
Figura 9-Reamostragem por vizinho mais próximo.

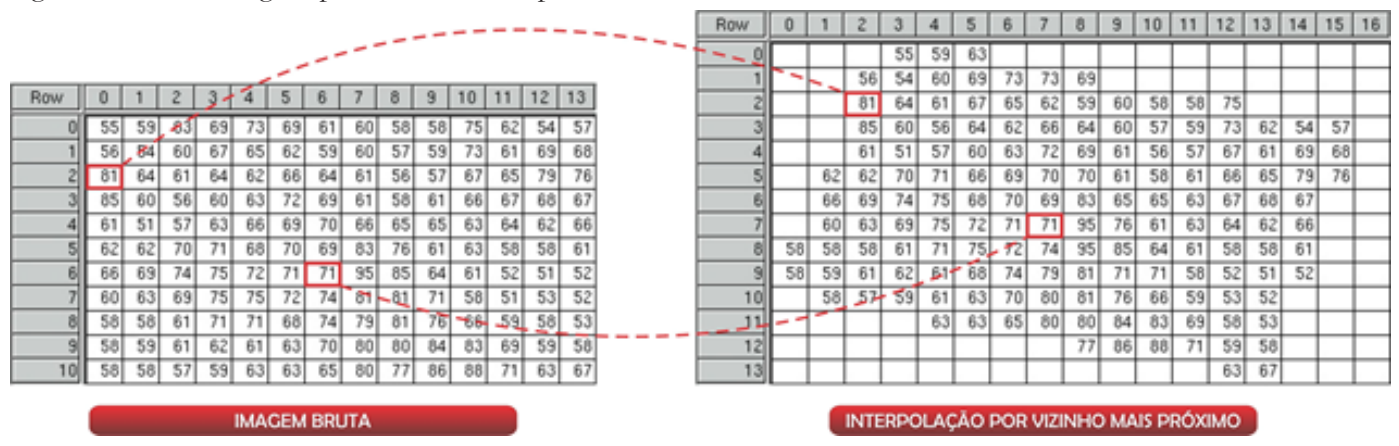

Fonte: Adaptado de Ramsey (1998a).

Todavia, Baboo e Devi (2010) e Goshtasby (2005) relatam como desvantagem o aparecimento do efeito "serrilhado" em feições lineares (como bordas, limites, linhas) horizontais e verticais que podem apresentar um aspecto de irregularidade na nova imagem. Isto ocorre quando a imagem é rotacionada na transformação geométrica. Outra desvantagem está relacionada ao desaparecimento de alguns valores de NC e a duplicação de outros, produzindo a descontinuidade em algumas feições, principalmente as lineares, que tinha a aparência contínua na imagem de origem. Por isto, considera-se a existência de pequena alteração no histograma da imagem.

\section{Interpolação Bilinear}

Este método realiza três interpolações lineares (duas ao longo das linhas e uma na direção das colunas) ao longo dos quatro pixels mais próximos da imagem original, para determinar o valor do pixel da imagem de saída (LIU; MASON, 2009; RAMSEY, 1998b; RICHARDS; JIA, 2006).

Este processo altera os valores originais do pixel e cria inteiramente novos valores digitais na nova imagem.

De acordo com Baboo e Devi (2010) isto pode ser considerado uma desvantagem para processamento digital de imagem de sensoriamento remoto como a análise detalhada do histograma, devido a redução do contraste entre os alvos, ocasionando uma suavização nas bordas; e consequentemente inviabilizando realizar a sua classificação com base na análise espectral dos alvos.

Para Goshtasby (2005) a vantagem deste método está no efeito de suavização entre as bordas e não apresenta o efeito serrilhado visual.

A Figura 10 comprova o resultado deste método, apresentando os valores dos NC de pixel da nova imagem.

\section{Convolução cúbica}

Emprega cinco interpolações polinomiais do terceiro grau sobre os dezesseis pixels que cercam o pixel da imagem de saída, sendo quatro ao longo das linhas e a quinta na direção das colunas (RAMSEY, 1998c; RICHARDS \& JIA, 2006).

De acordo com Campbel e Wynne (2011), normalmente, o resultado visual deste método é muito mais atraente do que os de outros dois métodos anteriores, porém, os valores dos NC são mais alterados também. Todavia, para se ter um bom resultado, recomenda-se utilizar um número maior de PC (CAMPBELL; WYNNE, 2011).

Para Baboo e Devi (2010) e Goshtasby (2005) esta reamostragem produz uma imagem visualmente 
Figura 10-Reamostragem por interpolação bilinear.
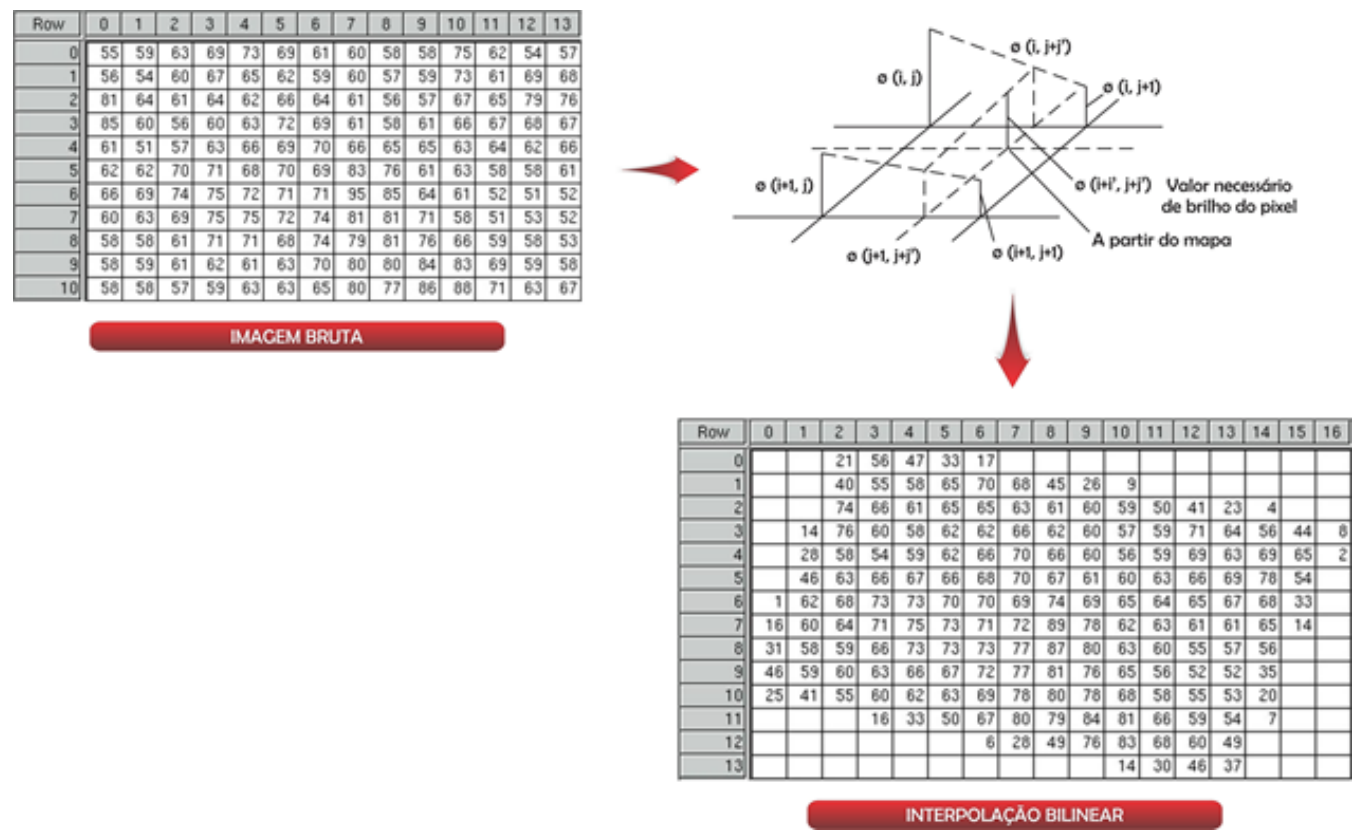

Fonte: Adaptado de Ramsey (1998b).

Figura 11-Convolução cúbica.
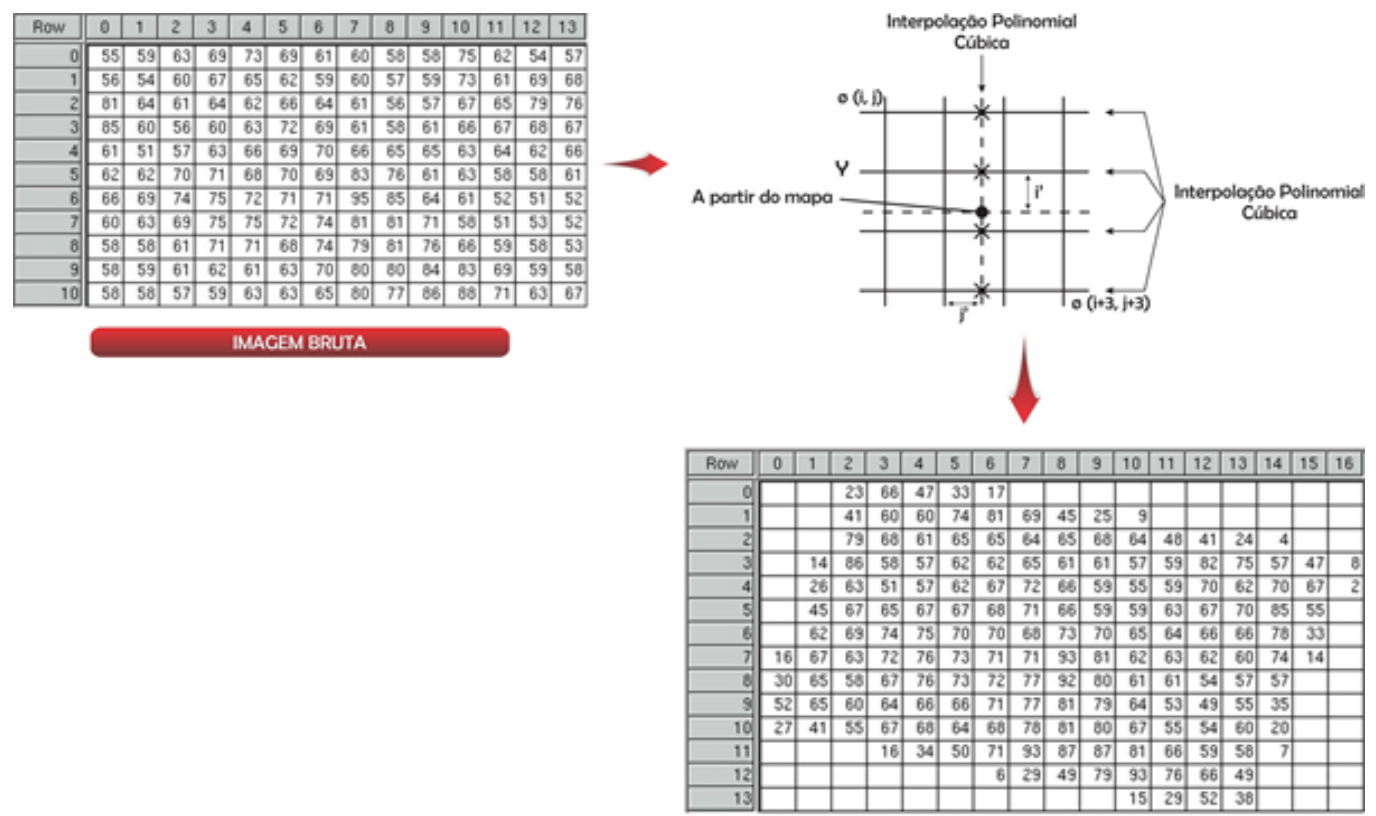

INTERPOLACGAO POR CONVOLUCGAO CUBICA

Fonte: Adaptado de Ramsey (1998c).

\section{Considerações Finais}

O georreferenciamento é uma das primeiras e principais etapas no processamento da informação espacial, pois incide diretamente na sua localização e na precisão cartográfica e, por consequência, na qualidade das demais análises. O Fluxograma abaixo apresenta as principais etapas do georreferenciamento (Figura 12).

Geografia Ensino \& Pesquisa, v. 18, n.3, p. 85-102, set./dez. 2014.

Melo, D. H. C. T. B.; Volpi, E. M.; Silva, H. M. da; Menezes, L. A.;
Moura, P. V. 
Figura 12-Fluxograma com as principais etapas do georreferenciamento

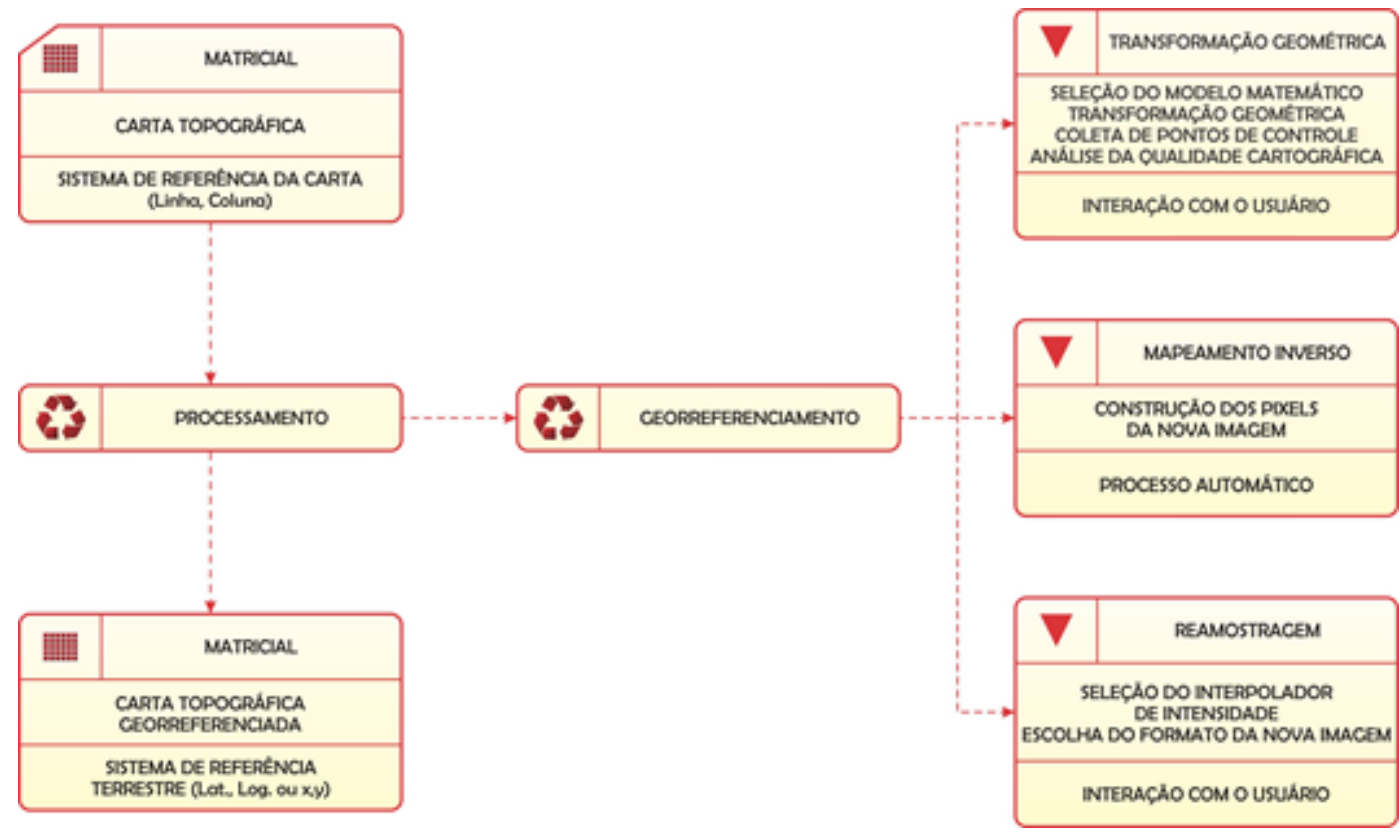

Fonte: elaborado pelos autores.

Resumidamente, o georreferenciamento envolve três etapas: na primeira etapa, a transformação geométrica, estabelece uma relação entre as coordenadas da imagem (linha e coluna) e as coordenadas terrestres (latitude e longitude ou x e y), que abrange a seleção do modelo matemático, coleta de pontos de controle e análise da qualidade cartográfica.

A segunda etapa, realizada automaticamente, atende ao mapeamento inverso, que efetua a reconstrução dos pixels da imagem, para que sejam reamostrados os tons de cinza, por meio de interpolação (terceira e última etapa).

\section{Agradecimentos}

À Fundação Carolina por se tratar de uma instituição que prioriza o fomento das relações culturas e a cooperação em matéria educativa e científica entre a Espanha e os países das Comunidades de Nações Iberoamericanas, e ao Instituto de Geociência da Universidade Federal da Bahia pela contribuição e valorização dos programas de extensão universitária.

\section{Referências}

ANDERSON, Paul S. (Coord.). Princípios de cartografia básica. Rio de Janeiro: Fundação IBGE. 1982. Não paginado. Disponível em: < http:// lilt.ilstu.edu/psanders/Cartografia/cartografia.html> Acesso em: 10 dez. 2013.

ARIKA, Hideo. Refinamento da correção geométrica de imagens digitais TM Landsat através da modelagem de efeito, utilizando feições retas como controle. 1990. 97 fls. Dissertação (Mestrado em Ciências) - Pós-Graduação em Ciências Geodésicas, Universidade Federal do Paraná, Curitiba, 1990.

Geografia Ensino \& Pesquisa, v. 18, n.3, p. 85-102, set./dez. 2014

Decifrando o Decifrando o
georreferenciamento

BABOO, S. Santhosh; DEVI, M. Renuka. An analysis of different resampling methods in Coimbatore, District. Global Journal of Computer Science and Technology, Delaware (USA), v.10, n. 15, p. 61-66, dec. 2010. Disponível em: < http://computerresearch.org/stpr/index.php/gicst/article/ view/474/433> Acesso em: 20 ago. 2013.

BOUTOURA, Chryssoula; LIVIERATOS, Evangelos. Some fundamentals for the study of the geometry of early maps by comparative methods. e-Perimetron: International web jorunal on sciences and technologies affined to history of cartography and maps, Thessaloniki (GR), v. 01 , n. 01, p. 60-70, jan./fev./mar. 2006. Disponível em: < http://www.e-perimetron.org/Vol_1_1/Boutoura_Livieratos/1_1_Boutoura_Livieratos.pdf> Acesso em: 15 out. 2013.

BRASIL. Decreto $\mathbf{n}^{\mathbf{0}} \mathbf{8 9 . 8 1 7}$ de 20 de junho de 1984. Estabelece as Instruções Reguladoras das Normas Técnicas da Cartografia Nacional. Diário Oficial da União, Brasilia, D.F., 22 jun. 1984, Seção 1,p 4. Disponível em: < http://www.jusbrasil.com.br/diarios/3423831/pg-4-secao-1-diario-oficial-da-uniao-dou-de-22-06-1984> Acesso em: 21 out. 2013. 
Portaria Inmetro $\mathbf{n}^{\mathbf{0}} 136$ de 6 de setembro de 2005. Adota, no Brasil, o Vocabulário Internacional de Termos de Metrologia Legal, em anexo, baseado no documento elaborado pela Organização Internacional de Metrologia Legal, com a devida adaptação ao nosso idioma, às reais condições existentes no País e às ja consagradas pelo uso. Diário Oficial da União, Brasilia, D.F., 13 set. 2005, Seção 1, p 47- 48. Disponível em: < http://www. jusbrasil.com.br/diarios/741275/pg-47-secao-1-diario-oficial-da-uniao-dou-de-13-09-2005> Acesso em: 21 out. 2013.

Decreto $\mathbf{n}^{\mathbf{0}} \mathbf{6 . 6 6 6}$ de 27 de novembro de 2008. Institui, no âmbito do Poder Executivo federal, a Infra-Estrutura Nacional de Dados Espaciais - INDE, e dá outras providências. Diário Oficial da União, Brasilia, D.F., 28 nov. 2008, Seção 1, p 57. Disponível em: < http://www.jusbrasil.com.br/ diarios/906472/pg-57-secao-1-diario-oficial-da-uniao-dou-de-28-11-2008> Acesso em: 20 nov. 2013.

BRITO, Jorge Luís Nunes e Silva; COELHO FILHO, Luiz Carlos Teixeira. Fotogrametria digital. Rio de Janeiro: IME. 2002. Disponível em: < http://www.efoto.eng.uerj.br/br/livro-de-fotogrametria/25> Acesso em: 15 out. 2013.

BRITO, Nataliente Mesquita et al. Avaliação da exatidão e da precisão de métodos de análise de resíduos de pesticidas mediante ensaios de recuperação. Pesticidas: Revista de Ecotoxicologia e Meio Ambiente, Curitiba, v. 12, n. 0, p 155-168, jan./dez. 2002. Disponível em: < http://ojs.c3sl.ufpr.br/ojs/ index.php/pesticidas/article/view/3157/2530> Acesso em: 7 ago. 2013.

CAMPBELL, James B.; WYNNE, Randolph H. Introduction of Remote Sensing. 5 ed. New York: Guilford Press, 2011. 667 p.

CASACA, João; MATOS, João; BAIO, Miguel. Topografia geral. 5 ed. Lisboa: Lidel, 2005. 408 p.

CONGALTON, R. G.; GREEN, K. The ABCs of GIS: an introduction to geographic information systems. Journal of Forestry, Bethesda (EUA), 90, n. 11, p 11-20, nov. 1992

CONSEl HO NACIONAL DE CARTOGRAFIA (CONCAR). Perfil de Metadados Geoespaciais do Brasil: conteúdo de Metadados Geoespaciais em conformidade com a norma ISO 19115:2003. 2009. Não paginado. Disponível em: $<$ http://www.sieg.go.gov.br/downloads/Perfil_de_ Metadados.pdf > Acesso em: 15 set. 2013

Perfil de Metadados Geoespaciais do Brasil. 2011. Não paginado. Disponível em: < http://www.concar.ibge.gov.br/arquivo/111@ Perfil_MGB_homologado_nov2009_v1.pdf> Acesso em: 20 out. 2013.

COSTA, Antonio Fernando Branco; EPPRECHT, Eugênio Kanh; CAPINETTI, Luiz Cesar Ribeiro. Controle estatístico de qualidade. 2 ed. São Paulo: Atlas, 2009.336 p.

CUARTERO, A.; FELICISIMO, A. M. Rectificación y ortorrectiticación de imágenes de satélite: análisis comparativo y discusión. Geofocus, Madrid, n. 3, p 45-57, 2003. Disponível em: < http://geofocus.rediris.es/docPDF/Articulo3_2003.pdf>. Acesso em: 26 ago. 2013.

DALAZOANA, Regiane; FREITAS, Silvio Rogério Correia de. Efeitos na cartografia devido a evolução do Sistema Geodésico Brasileiro e adoção e um referencial geocêntrico. Revista Brasileira de Cartografia, Brasilia, n. 54, p 66-76, dez. 2002. Disponível em: < http://www.lsie.unb.br/rbc/index $\mathrm{php/rbc/article/view/190/173>} \mathrm{Acesso} \mathrm{em:} 25$ ago. 2013.

D’ALGE, Júlio César Lima. Cartografia para Geoprocessamento. In: CÂMARA, Gilberto; DAVIS, Clodoveu; Antônio Miguel Vieira (Org.). Introdução a ciência da geoinformação. São José dos Campos: INPE, 2013. Não paginado. Disponível em: <http://www.dpi.inpe.br/gilberto/livro/ introd/cap6-cartografia.pdf> Acessado em: 05 nov. 2013

FONSECA, Leila M. G.; MANJUNATH, B. S. Registration techniques for multisensor remotely sensed imagery. Photogrammetric Engineering \& Remote Sensing, Bethesda, v. 62, n. 9, p 1049-1056, sep. 1996. Disponível em: http://asprs.org/a/publications/pers/96journal/september/1996_ sep_1049-1056.pdf $>$ Acesso em 20 mar. 2014

GOSHTASBY, A. Ardeshir. 2-D and 3-D image registration: for Medical, Remote Sensing and Industrial Applications. Hoboken: John Wiley \& Sons, 2005. 270 p.

IIIFFE, Jonathan; LOTT, Roger Datums and map projections: for remote sensing, GIS, and surveying. Boca Raton: CRC Press LLC, 2008.208 p.

INSTITUTO BRASILEIRO DE GEOGRAFIA E ESTATÍSTICA (IBGE). Manual de normas técnicas, especificações e procedimentos técnicos para a Carta Internacional do Mundo, ao milionésio - CIM: 1:1.0000.00. Rio de Janeiro: Fundação IBGE, 1993. 63 p. (Manuais Técnicos em Geociências, n. 2). Disponível em: < http://biblioteca.ibge.gov.br/visualizacao/livros/liv23847.pdf> Acesso em: 10 jan. 2013.

INSTITUTO BRASILEIRO DE GEOGRAFIA E ESTATÍSTICA (IBGE). Noções Básicas de Cartografia. v. 1. Rio de Janeiro: Fundação IBGE, 1999. 130 p.(Manuais Técnicos em Geociências, n. 8). Disponível em: < http://biblioteca.ibge.gov.br/visualizacao/livros/liv8595_v1.pdf> Acesso em: 10 jan. 2013.

. Introdução ao processamento digital de imagens. Rio de Janeiro: Fundação IBGE, 2001. 91 p. (Manuais Técnicos em Geociências, n. 9). Disponível em: < http://biblioteca.ibge.gov.br/visualizacao/livros/liv780.pdf> Acesso em: 10 jan. 2013.

.Resolução IBGE/PR/n. 25 de fevereiro de 2005. Altera a caracterização do Sistema Geodésico Brasileiro. Página Oficial do IBGE. Rio de Janeiro, R. J. 25 de fev. 2005. Disponível em: < ftp://geoftp.ibge.gov.br/documentos/geodesia/projeto_mudanca_referencial_geodesico/legislacao/ rpr_01_25fev2005.pdf> Acesso em: 10 jan. 2013

Sistema de Referência. 2011. Disponível em: < ftp://geoftp.ibge.gov.br/documentos/geodesia/sisref_2.pdf> Acesso em: 10 jan. 2013.

Geodésia. 2013. Disponível em: http://wwwibge.gov.br/home/geociencias/geodesia/default.shtm> Acesso em: 5 dez. 2013.

LIU, Jian Guo; MASON, Philippa. J. Essential image processing and GIS for remote sensing. Oxford: John Wiley \& Sons, 2009. 460 p.

LLOPIS, Juan Peña. Sistemas de información geográfica aplicados a la gestión del territorio: entrada, manjeo, análisis y salida de dados espaciales. Alicante: Editorial Club Universitario, 2006. 310 p.

LUIZ, S.; OLIVEIRA, C. G.; OKIDA, R. Comparacão entre diferentes métodos de correção geométrica em imagem Radarsat-1 no FLONA Tapajós. In: SIMPÓSIO BRASILEIRODE SENSORIAMENTO REMOTO,11.(SBSR), 2003, Belo Horizonte. Anais... São Josédos Campos: INPE, 2003. p. 325-332 CD-ROM, Online. ISBN 85-17-00017-X. Disponível em: <http://urlib.net/ltid.inpe.br/sbsr/2002/11.14.17.05>. Acesso em: 03 maio 2014.

Geografia Ensino \& Pesquisa, v. 18, n.3, p. $85-102$, set./dez. 2014

Melo, D. H. C. T. B.; Volpi, E. M.; Silva, H. M. da; Menezes, L. A. 
MARCATO JUNIOR, José et al. Orientação de imagens CBERS-2B usando o modelo rigoroso de colinearidade com dados orbitais. Boletim de Ciências Geodésicas, Curitiba, v. 17, n. 3,p 401-416, jul./set. 2011. Disponível em: < http://dx.doi.org/10.1590/S1982-21702011000300005> Acesso em: 25 ago. 2013.

MENESES, Paulo Roberto; ALMEIDA, Tati de (Org). Introdução ao Processamento de imagens de sensoriamento remoto. Brasilia: UNB/CNPq, 2012. 266 p. Disponível em: < http://www.cnpq.br/documents/10157/56b578c40fd5-4b9f-b82a-e9693e4f69d8> Acessado em: 25 ago. 2013.

MOIK, Johannes G. Digital processing of remotely sensed images. Washington: NASA, 1980. 330 p. Disponível em: < https://archive.org/ details/nasa_techdoc_19810011960> Acesso em: 25 ago. 2013.

MONICO, João Francisco Galera; et al. Acurácia e precisão: revendo os conceitos de acurada. Boletim de Ciências Geodésicas, Curitiba, v. 15, n. 3, p 469-483, jul./set. 2009. Disponível em: < http://ojs.c3sl.ufpr.br/ojs2/index.php/bcg/article/view/15513/10363> Acesso em: 25 ago. 2013.

MOURA, Ana Clara Mourão. A importância dos metadados no uso das Geotecnologias e na difusão da Cartografia Digital. In: SEMINÁRIO NACIONAL SOBRE MAPEAMENTO SISTEMÁTICO, 2, 2005, Belo Horizonte. Anais... Belo Horizonte: CONFEA/CREA. p 1-18.

NOVUS. Conceitos básicos de metrologia-Parte 1: diferença entre precisão e exatidão. 2012. Figura. Disponível em: $<$ http://www.novus.com.br/site/default. asp?TroncoID=053663\&SecaoID=273506\&SubsecaolD=0\&Template=../artigosnoticias/user_exibirasp\&ID=809133>Acesso em: 10 fev. 2014.

OAKLAND, John S. Gerenciamento da qualidade total. São Paulo: Nobel, 1994. 459 p.

RAMSEY, R. Douglas. Resampling methods: nearest neighbor. 1998a. Disponível em: < http://web.archive.org/web/20050117063931/http:// www.cla.sc.edu/geog/rslab/Rscc/mod5/5-2/nn.html> Acesso em: 10 fev. 2014.

RAMSEY, R. Douglas. Resampling methods: bilinear interpolation. 1998b. Disponível em: < http://web.archive.org/web/20050117063503/ http://www.cla.sc.edu/geog/rslab/Rscc/mod5/5-2/bl.html> Acesso em: 10 fev. 2014.

RAMSEY, R. Douglas. Resampling methods: cubic convolutin. 1998c. Disponível em: < http://web.archive.org/web/20050117063940/http:// www.cla.sc.edu/geog/rslab/Rscc/mod5/5-2/cc.html > Acesso em: 10 fev. 2014.

RICHARDS, John A.; JIA, Xiunping. Remote sensing digital image analysis: an introduction. 4 ed. Berlin: Springer, 2006.464 p.

SAMOHYL, Robert Wayne. Controle estatístico de qualidade. Rio de Janeiro: Elsevier, 2009. 352 p.

SANTIL, Fernando Luiz de Paula; QUEIROZ, Deise Elias Regina. Leitura e entendimento dos elementos contidos numa carta topográfica. Boletim de Geografia, Maringá, v. 14, n. 1, p 41-49, 1996a. Disponível em: < http://www.periodicos.uem.br/ojs/index.php/BolGeogr/article/ view/12884/7337> Acesso em: 25 ago. 2013.

SANTIL, Fernando Luiz de Paula; QUEIROZ, Deise Elias Regina. Produtos Cartográficos: algumas considerações. Boletim de Geografia, Maringá, v. 14, n. 1, p 51-57,1996b. Disponível em: <http://www.periodicosuem.br/ojs/index.php/BolGeogr/article/viewFile/12885/7338> Acesso em: 25 ago. 2013.

SANTOS, Suzana Daniela Rocha, et al. Consideracões sobre a utilização do PEC (Padrão de Exatidão Cartográfica) nos dias atuais. In: SIMPÓSIO BRASILEIRO DE CIÊNCIAS GEODÉSICAS E TECNOLOGICAS DA GEOINFORMAÇ̃̃O, 3, 2010, Recife. Anais... Recife: UFPE. p 1-5.

SCHOWENGERDT, Robert A. Remote Sensing: models and methods for image processing. 3 ed. Amsterdam: Elsevier, 2007.560 p.

SICKLE, Jan Van. Basic Gis Coordenates. 2 ed. Boca Ration: CRC Press, 2010. 192 p.

SILVA, Ardemiro de Barros Sistemas de Informações Geo-referenciadas: conceitos e fundamentos. Campinas, São Paulo, Brasil: Unicamp, 2003.236 p.

SILVA, George R. C.; MENDONCA, André. Metadados Geográficos. FOSSGIS, [S.I.], n. 4, p. 21-30, jan., 2012. Disponível em: < http://fossgisbrasil.com.br/wp-content/downloads/Revista_FOSSGIS_Brasil_Ed_04_Janeiro_2012.pdf> Acesso em: 25 ago. 2013.

SNYDER, John P. Map projections: a working manual. Washington: USGS, 1987. 385p. Disponível em: < http://pubs.er.usgs.gov/djvu/PP/ PP_1395.pdf> Acesso em: 25 ago. 2013

TEIXEIRA, Amandio Luís; MORETTI, Edmar; CHRISTOFOLETTI, Antonio. Introdução aos Sistemas de Informação Geográfica. Rio Claro: do Autor, $1992.80 \mathrm{p}$.

VEIGA, Luis Augusto Koenig; ZANETTI, Maria Aparecida Zehnpfenning, FAGGION, Pedro Luis. Fundamentos de Topografia. Curitiba: UFPR. 2012. 274 p. Disponível em: < http://www.cartografica.ufpr.br/docs/topo2/apos_topo.pdf> Acesso em: 10 ago. 2013.

YAROSLAVSKY, Leonid. Digital holography and digital image processing: principles, methods, algorithms. New York: SPRINGER SCIENCE + BUSINESS MEDIA, 2004. 600 p.

\section{Correspondência}

Geografia Ensino \& Pesquisa, v. 18 n.3, p. $85-102$, set./dez. 2014

Decifrando o georreferenciamento

\section{Danilo Heitor Caires Tinoco Bisneto Melo}

E-mail: danilo.melo@ufba.br

Recebido em 24 de julho de 2014.

Aceito para publicação em 25 de novembro de 2014. 